\title{
Start-up analysis methods for the diagnosis of rotor asymmetries in induction motors- seeing is believing
}

\author{
George Georgoulas, Vicente Climente-Alarcon, Member, IEEE, Leonidas Dritsas, Member, IEEE, \\ Jose A. Antonino-Daviu, Senior Member, IEEE and George Nikolakopoulos, Member, IEEE
}

\begin{abstract}
This article presents a qualitative analysis of different methods proposed for the diagnosis of broken rotor bars using the stator current during start-up operation. The slip dependent components, caused by the asymmetry, which is created by the breakage of rotor bar(s) and especially the left sideband harmonic (LSH) component, can create a distinctive pattern in a timefrequency plane. Short Time Fourier Transform, Wavelet analysis, and Wigner-Ville Distribution are evaluated using signals from motors operating in real industrial settings. The corresponding analysis presents the pros and the cons of these approaches for their potential application under realistic industrial conditions using the larger number of real life cases encountered in the literature.
\end{abstract}

\section{INTRODUCTION}

Induction motors are very common for industrial applications due to their low price and increased reliability. However an increased reliability does not mean completely fault free operation, especially taking into consideration the harsh operating conditions under which induction motors often operate. Therefore over the years a need emerged for monitoring induction motors in order to prevent anticipated failures due to electrical or mechanical faults.

As a result a number of methods have been proposed over the years trying to diagnose the condition of induction motors [1], [2]. Among the different types of induction motor faults, rotor related faults have attracted the most attention from the research community. One of the reasons is that if rotor faults go undetected they can propagate toward the adjacent bars culminating to a state that it might not be time to perform

This work was partially supported by the Spanish MINECO and FEDER program in the framework of the 'Proyectos I+D del Subprograma de Generación de Conocimiento, Programa Estatal de Fomento de la Investigación Científica y Técnica de Excelencia' (ref: DPI2014-52842-P) and the HORIZON 2020 Framework for Research and Innovation DISIRE under the Grant Agreement No. 636834 (http://spire2030.eu/disire/).

G. Georgoulas and G. Nikolakopoulos are with Control Engineering Group Department of Computer Science, Electrical and Space Engineering Luleå University of Technology, SE-97187 Luleå, Sweden, (phone: +46 (0)920 491298; e-mail: \{geogeo, geonik\}@ltu.se).

V. Climente-Alarcon is with the Department of Electrical Engineering and Automation, Aalto University, P. O. Box 13000, FI-00076 Aalto, Finland (e-mail: viclial@ieee.org).

L. Dritsas is with the Department of Electrical and Electronic Engineering Educators, School of Pedagogical and Technological Education, Athens, Greece (e-mail: dritsas@aspete.gr).

J. A. Antonino-Daviu is with the Instituto Tecnologico de la Energia, Universitat Politècnica de València, Camino de Vera s/n, 46022 Valencia, Spain (e-mail: joanda@die.upv.es). maintenance. For this type of faults, Motor Current Signature Analysis (MCSA) [3], is the most common tool for fault detection and diagnosis (FDD) primarily due to its noninvasive nature [4].

MCSA relies on the fact that the breakage of a bar produces a "faulty" component with characteristic frequencies given by the following equation:

$$
f_{b}=(1 \pm 2 \cdot k \cdot s) f_{s}, \quad k=1,2, \ldots
$$

where $f_{s}$ is the fundamental frequency and $s$ is the slip. Usually MCSA methods using the Fast Fourier Transform (FFT) or some other spectrum estimation method, try to detect one of the aforementioned component, namely the Lower (or Left) Sideband Harmonic (LSH), which is given for $k=1$ and taking the minus sign in eq. 1: $\left((1-2 \cdot s) f_{s}\right)[1]$.

On the other hand, MCSA despite its convenience, has some drawbacks, related to false alarms created by other phenomena (e.g. load torque oscillations), which leave their "fingerprints" at frequencies that can coincide with those caused by broken rotor bars [5], [4].

Transient-MCSA (TMCSA) came to complement traditional MSCA by focusing on the analysis of the start-up current [5], [7] using advanced signal processing methods [5], [7]-[9]. These methods try to quantify in some way the evolution, primarily of LSH. Ideally, the frequency of the LSH varies from $f_{s}$ to zero and back again close to $f_{s}$, depending on the value of slip at steady state [7].

This characteristic V like pattern is the main focus of this work. Even though this pattern has been investigated in other research attempts [10]-[14], this is the first time, to the authors' best knowledge, that three different time-frequency decomposition methods are compared, in a qualitative manner, using exclusively data coming from industrial motors. The three methods were selected primarily due to their wide use in the engineering field and due to their ease for parameter tuning, when compared to other newly proposed methods, such as the Empirical Mode Decomposition (EMD). In other words they could be considered as "off-the-shelf" methods for a practicing engineer. Here it should be noted that practicing engineers are sometimes unwilling to use tools that do not understand, while on the other hand their confidence on an automatic method increases when the method can provide compelling evidence about the decision reached. That is the reason that the few commercial condition monitoring devices provide 
among other things graphical displays that depict the spectrum analysis of the stator current [15]-[17]; there, a peak at a "fault" frequency can alert for an upcoming failure.

In a similar manner, depicting the $\mathrm{V}$ pattern in case of start-up transient can further enhance the reliability of a method that is based on the analysis of the starting-up current. In both cases "seeing is believing", a concept that is starting to attract more attention in the machine learning community [18].

The rest of the paper is structured as follows: Section II provides a brief background for each one of the three methods. Section III presents the experimental procedure followed and the produced result in the form of time frequency(scale) plots along with a qualitative assessment of these results and finally section IV concludes this work discussing some directions for future work.

\section{METHODS}

In this article, three time-frequency analysis methods are used namely, the Short Time Fourier Transform (STFT), the Continuous Wavelet Transform (CWT) employing the complex Morlet wavelet and the (pseudo) Wigner-Ville Distribution (WVD). The same set of methods were employed in one of the earliest studies in the field of TMCSA [19].

\section{A. Short Time Fourier Transform}

The STFT or the Window Fourier Transform (WFT) is one of the simplest and most widely used methods in practice, for analyzing a signal in time and frequency, even though it is not the first chronologically introduced. As its name implies, WFT consists of the application of the Fourier transform over a sliding window $w(t)$ on the signal $x(t)$ under investigation.

$$
X(t, \omega)=\int_{-\infty}^{\infty} x(\tau) w(\tau-t) e^{-j \omega \tau} d \tau
$$

STFT creates a time frequency representation, which is called spectrogram $S(t, \omega)$.

$$
S(t, \omega)=|X(t, \omega)|^{2}
$$

In general, STFT it is easy to implement using the FFT. The use of FFT makes the spectrogram a very user friendly tool for engineers who are usually familiar with its application. In fact it was the first tool to be used for the analysis of the start-up transient of induction motors with and without rotor asymmetry [20]. From another point of view, one of the limitations of the STFT is the trade-of between frequency and time resolution.

\section{B. Continuous wavelet transform}

A wavelet $\psi(t)$ is, a localized waveform (a short-term duration wave) that satisfies certain conditions [21]. The continuous wavelet transform of a signal $x(t)$ is given as follows:

$$
T(a, b)=\frac{1}{\sqrt{a}} \int_{-\infty}^{\infty} x(t) \cdot \psi^{*}\left(\frac{t-b}{a}\right) d t
$$

where $a$ is called the scale parameter, $b$ is the translation parameter and the asterisk indicates that the complex conjugate of the wavelet function is used in the transform. The resulting wavelet coefficients provide a time-scale representation of the original signal, usually through the scalogram $E(a, b)$ :

$$
E(a, b)=|T(a, b)|^{2},
$$

which gives the relative contribution of the signal energy at a given location $b$ and for a specific scale $a$.

Among the various "mother" wavelets, the complex Morlet wavelets are usually used for time-frequency analysis [22]:

$$
\psi(t)=\frac{1}{\sqrt{\pi f_{b}}} \exp \left(j 2 \pi f_{c} t-\frac{t^{2}}{f_{b}}\right)
$$

where $f_{c}$ is the central frequency of the wavelet and $f_{b}$ is the bandwidth. The wavelet transform creates a time-scale representation; however a correspondence between scale and frequency exists through the notion of "pseudo-frequency":

$$
f=\frac{f_{c}}{a} f_{\text {samp }}
$$

where $f_{\text {samp }}$ is the sampling frequency in $\mathrm{Hz}$.

\section{Wigner-Ville distribution}

The WVD $W(t, \omega)$ is the first method used for the time frequency decomposition of signals [23], originally developed within the quantum thermodynamics field [24]:

$$
W(t, \omega)=\int_{-\infty}^{\infty} x\left(t+\frac{\tau}{2}\right) x^{*}\left(t-\frac{\tau}{2}\right) e^{-j \omega \tau} d \tau
$$

The WVD has a number of desired (theoretical) properties, including increased resolution [25]. However the WVD is a quadratic method giving rise to interference terms, which can create serious problems in the interpretation of the results, especially in the presence of noise or in the presence of multiple frequency components. To alleviate the interference problem the pseudo-WVD can be used which applies a smoothing window $h(\cdot)$, trading some of the properties of the WVD for a reduction of the interference terms:

$$
W_{p}(t, \omega)=\int_{-\infty}^{\infty} h(t) x\left(t+\frac{\tau}{2}\right) x^{*}\left(t+\frac{\tau}{2}\right) e^{-j \omega \tau} d \tau
$$
[27].

The pseudo-WVD is calculated using the TFTB Toolbox 


\section{EXPERIMENTAL PROCEDURE-RESULTS}

\section{A. Data}

In this work, six start up currents from six large motors are tested. A summary of their characteristics is given in the following Table I. It should be noted that due to the proprietary nature of the data, very few information can be provided. All motors had some degree of asymmetry, which was verified either after disassembling the motor or through further dedicated condition monitoring tests. The fundamental frequency in all cases is $50 \mathrm{~Hz}$.

\section{B. Preprocessing}

All currents are normalized by division with their corresponding maximum absolute value. Since the fundamental frequency creates problems with the introduction of interference terms, in the case of WVD distribution even by the use of a smoothing window, the fundamental frequency was removed using a combination of two elliptical filters [13]: an elliptic notch filter with the notch located at $50 \mathrm{~Hz}$ and a low pass elliptic filter with a cut-off frequency at $45 \mathrm{~Hz}$. For a fair comparison, the same process for eliminating the fundamental component is employed before the application of STFT and CWT.

\section{Results}

The results of the application of the three time-frequency analysis methods are depicted in Fig. 1-6. In each figure, the top graph depicts the start-up current, followed by the spectrogram, the scalogram and the pseudo-WVD. In all cases a logarithmic scale is used.

M1: The M1 motor is a water feeding pump, with verified asymmetry. As it can be seen in Fig. 1 all three methods easily capture the evolution of the faulty harmonic. In this specific case, the pseudo-WVD offers the highest resolution.

M1: The M2 motor is a double speed motor driving a fume exhausting fan. The motor has a very low asymmetry level. Both the spectrogram and the scalogram can show that there is some sort of asymmetry in the rotor but in both of them spurious other frequencies are spread across the timefrequency/scale plane, Fig. 3. These components create a great deal of interference, which completely hides the faulty component in the pseudo-WDV (bottom of Fig. 2)

M3: The M3 motor is installed as a high-speed coal mill facility. It has a clear asymmetry, which is easily detected by all three representations, Fig. 3. The asymmetry is so profound that even though other frequency components are present, which create interference terms in the pseudo-WVD, the faulty component is still visible. The created pattern in all cases does not exactly follow the $\mathrm{V}$ shape, bringing forward the issue discussed in the next section: a V pattern should be expected in a slip-frequency plane while some distortion should be expected in a time-frequency plane.

M4: M4 is similar to M2, operating under similar settings too, but this time the level of asymmetry is much higher. As in the case of M2, the faulty component is depicted in both the spectrogram and the scalogram, while the interference terms completely mask the presence of the faulty component in the pseudo-WVD, Fig. 4.

M5: M5 is installed in a coal mill. Due to the quite fast starting time, only the right branch of the $\mathrm{V}$ pattern is captured, while the left one is masked by the interference created by the electromechanical transient, Fig. 5. This is a phenomenon that has been observed also in simulations and during the analysis of fast start-ups in laboratory environments [26].

M6: M6 drives a fan. All three methods are able to capture the evolution of the faulty component, Fig. 6. It is worth noting that a second $\mathrm{V}$ like pattern component appears which as in the case of M3 reminds us that the $\mathrm{V}$ pattern is an undisputable indicator of rotor asymmetry (only) in a slipfrequency plane.
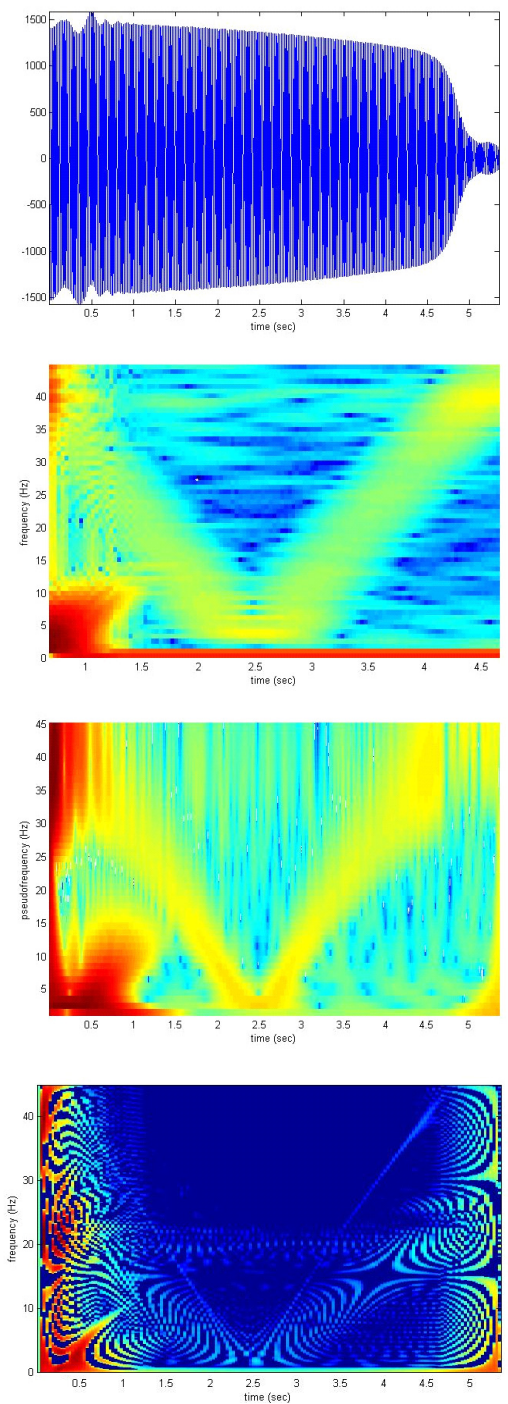

Figure 1. The start-up current, the spectrogram, scalogram and the pseudoWVD of motor M1 - water feeding pumb. All three methods are able to capture the characteristic $\mathrm{V}$ pattern. 

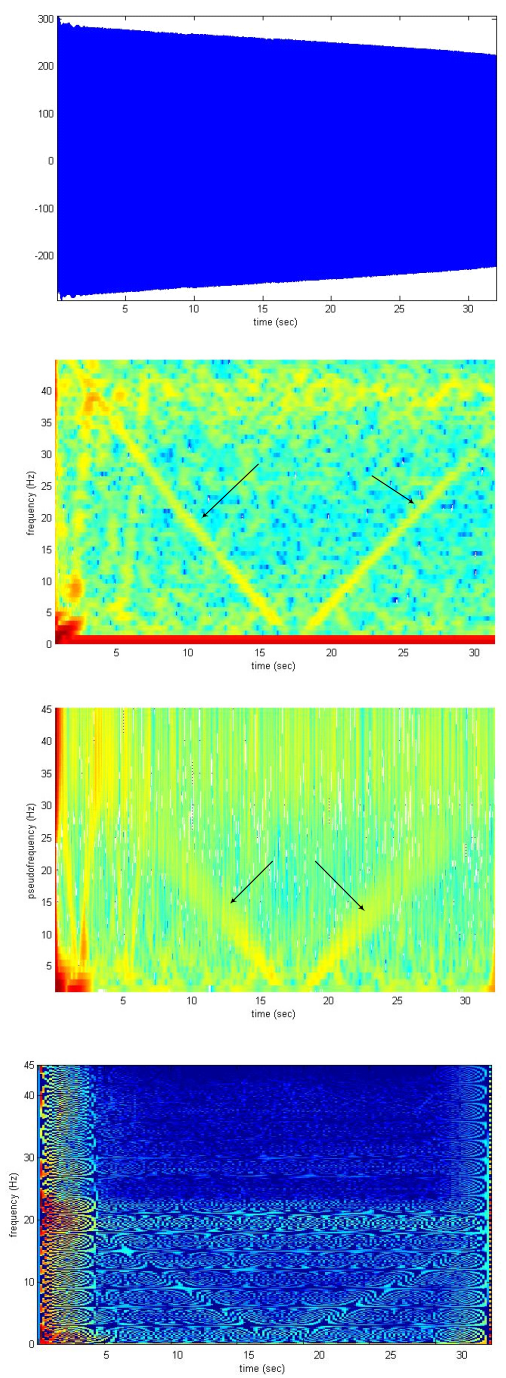

Figure 2. The start-up current, the spectrogram, scalogram and the pseudoWVD of motor M2 - double fed motor driving a fume exhausting pub. The low amplitude of the faulty component (very low asymmetry) combined with the presence of other frequncy components create such an amount of intereference term that completely mask its presense in the pseudo-WVD.

TABLE I. MOTORS

\begin{tabular}{|l|l|l|l|}
\hline \multirow{2}{*}{ Name } & \multicolumn{3}{|c|}{ Motor Characteristics } \\
\cline { 2 - 4 } & \multicolumn{1}{|c|}{ operation } & \multicolumn{1}{c|}{ condition } & Characteristics \\
\hline M1 & Water feeding pump & $\begin{array}{l}\text { Certain } \\
\text { asymmetry }\end{array}$ & $\begin{array}{l}2984 \mathrm{rpm} \\
1 \text { pole pair }\end{array}$ \\
\hline M2 & $\begin{array}{l}\text { double speed motor. } \\
\text { Fume exhausting fan }\end{array}$ & $\begin{array}{l}\text { Very low } \\
\text { asymmetry }\end{array}$ & $\begin{array}{l}740 / 590 \mathrm{rpm} \\
5 \text { pole pairs at } \\
\text { the lower speed }\end{array}$ \\
\hline M3 & High speed coal mill & $\begin{array}{l}\text { Clear } \\
\text { asymmetry }\end{array}$ & $\begin{array}{l}740 \mathrm{rpm} \\
4 \text { pole pairs }\end{array}$ \\
\hline M4 & double speed motor. & $\begin{array}{l}\text { Certain } \\
\text { level of } \\
\text { asymmetry }\end{array}$ & $\begin{array}{l}740 / 590 \mathrm{rpm} \\
5 \text { pole pairs at } \\
\text { the lower speed }\end{array}$ \\
\hline M5 & Fume exhausting fan & $\begin{array}{l}\text { Certain } \\
\text { asymmetry }\end{array}$ & $740 \mathrm{rpm}$ \\
\hline M6 & Mill fan & $\begin{array}{l}\text { Certain } \\
\text { asymmetry }\end{array}$ & $1492 \mathrm{rpm}$ \\
\hline
\end{tabular}

a. Due to confidentiality issues, no full disclosure of motor characteristics is possible
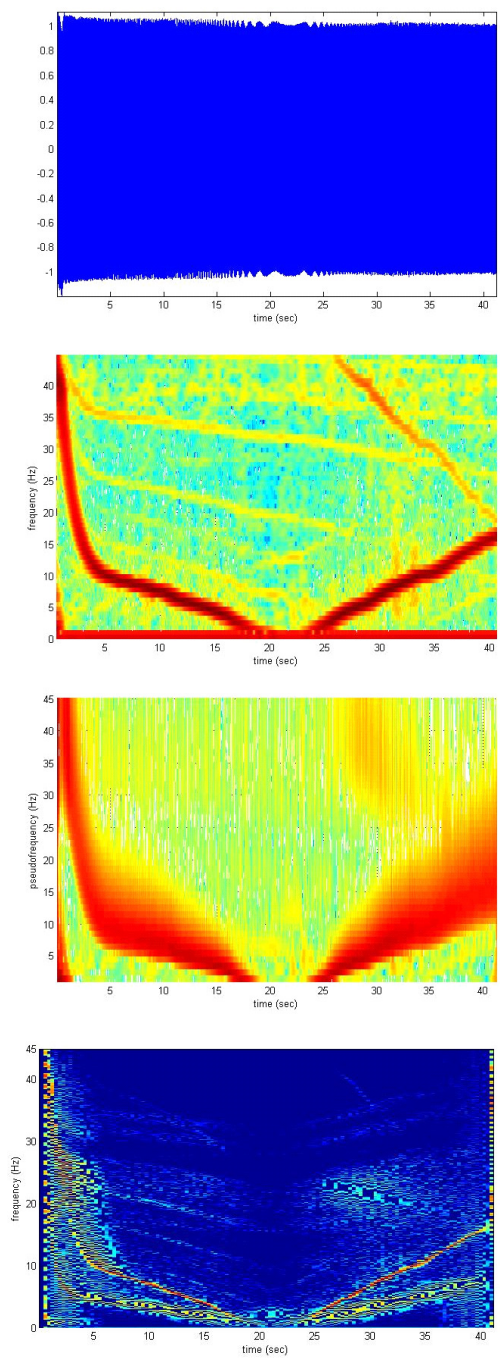

Figure 3. The start-up current, the spectrogram, scalogram and the pseudoWVD of motor M3 - high speed coal mill facility. The faulty component is clearly visible but does not exaclty follow a $\mathrm{V}$ pattern since there is not a linear correspondance between time evolution and slip evolution.

\section{CONCLUSIONS}

This work presents a qualitative analysis of three different time-frequency methods for the analysis of the start-up currents using a very large, compared to what is encountered in the relative literature, number of industrial motors.

The results are somewhat similar to those presented in an earlier study [19] indicating that among the three methods the pseudo-WVD can face problems at the presence of noise, which is very common in industrial settings. In situations like these further preprocessing is needed in order of the pseudoWVD to be effective [28]. This approach was not pursued in this work, which mainly focuses on the use of "off-the-shelf" methods for the analysis of the start-up current. The other two two methods captured the faulty component in all six cases. Between the two no clear advantage could be established of 
one of the methods over the other. Therefore as a general rule of thumb both methods can be used in case of real life applications. If from the resulting time-frequency planes it is clear that the level of noise is not high, the pseudo-WVD can be used as a complementary means to provide higher resolution.

The analysis also revealed that for increasing the reliability of the use of this kind of methods, the slip information should also be included either directly through physically measuring the speed or indirectly through estimation procedures [29]. The reason is that the anticipated $\mathrm{V}$ pattern might appear distorted in the time-frequency plane (Fig. 3) or there might be a need to be discriminated from other V-like patterns (Fig. 6) which are not related to the LSH. For the latter the inclusion of higher bands could be beneficial. This path will be investigated in future work.
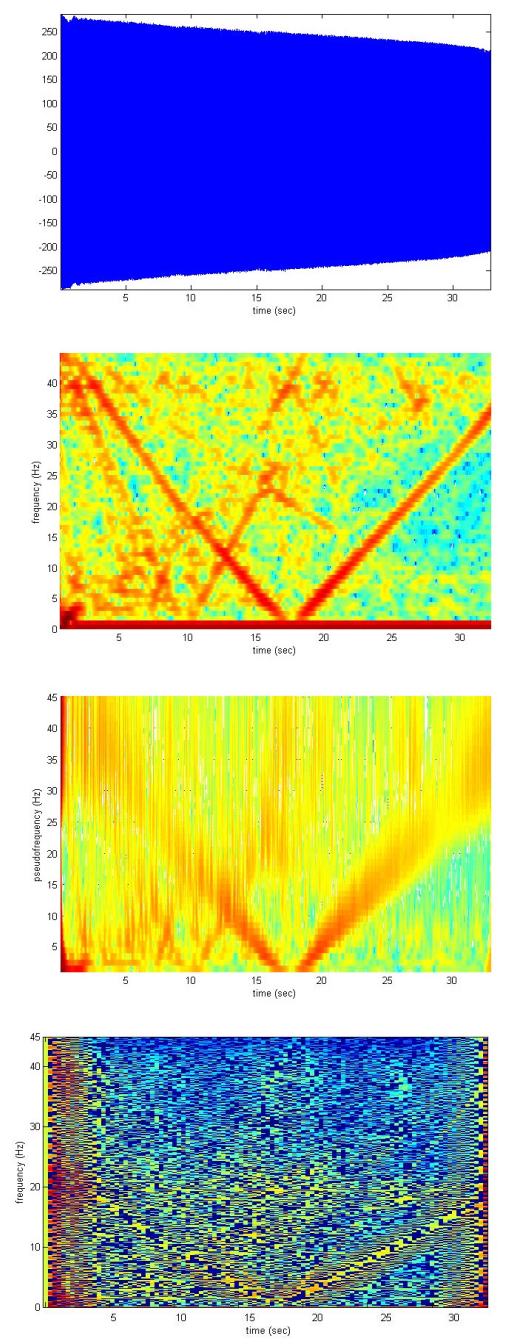

Figure 4. The start-up current, the spectrogram, scalogram and the pseudoWVD of motor M4 - similar motor and industrial environment to M2. As in Fig. 3 the faulty compoenent cannot be depicted by the pseudo-WVD due to interference terms.
In future work slip estimation will be integrated in the analysis while an automatic procedure for detecting the presence of an asymmetry will be used. This however does not mean that the depictions of the time-frequency (or slipfrequency) will become obsolete, since as it was pointed out in the introduction, "seeing is believing".
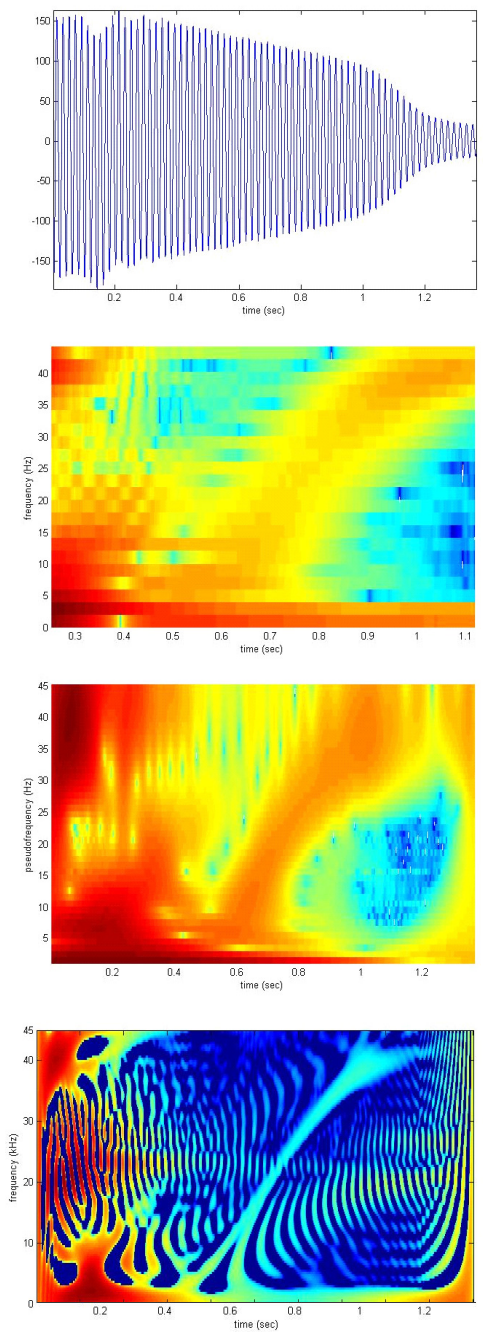

Figure 5. The start-up current, the spectrogram, scalogram and the pseudoWVD of motor M5 - coal mill motor. All three methods are able to capture only part of the $\mathrm{V}$ pattern. The first half is hidden because it is very close to the electromechanical intereference created by the starting of the motor.

\section{REFERENCES}

[1] W. T. Thomson, M. Fenger, "Current signature analysis to detect induction motor faults" IEEE Industry Appl. Magazine, pp. 26-34, July/August 2001..

[2] P. Zhang, Y. Du, T.G. Habetler, and B. Lu, "A Survey of condition monitoring and protection methods for medium voltage induction Motors," IEEE Trans. Energy Convers., vol. 47, no. 1, pp. 34-46, 2011.

[3] M. Riera-Guasp, J.A. Antonino-Daviu, and G.A. Capolino, "Advances in electrical machine, power electronic, and drive condition monitoring and fault detection: State of the art," IEEE Trans. Ind. Electron., vol. 62, no. 3, pp.1746-1759, 2015. 

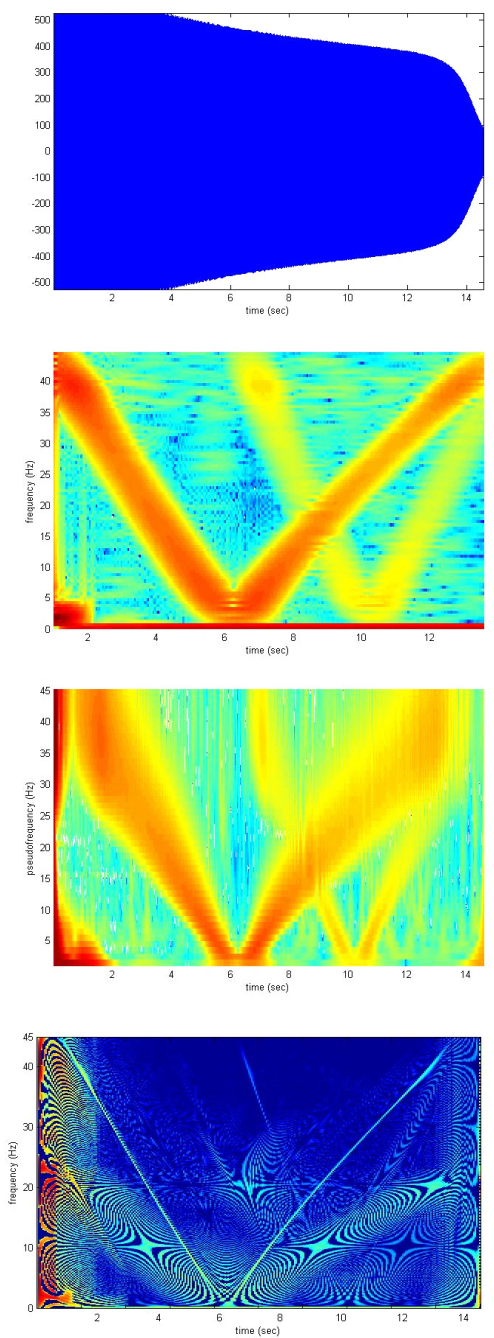

Figure 6. The start-up current, the spectrogram, scalogram and the pseudoWVD of motor M6 - driving a mill fan. All three methods are able to capture the characteristic $\mathrm{V}$ pattern. A second $\mathrm{V}$ pattern is also visible which should not be confused to the LSH.

[4] M. B. K.Bouzid, and G Champenois, "New expressions of symmetrical components of the induction motor under stator faults," IEEE Trans. Ind. Electron., vol. 60, no. 9, pp. 4093-4102, Sept. 2013.

[5] J. A. Antonino-Daviu, M. Riera-Guasp, J. R. Folch, and M. Pilar Molina Palomares, "Validation of a new method for the diagnosis of rotor bar failures via wavelet transform in industrial induction machines," IEEE Trans. Ind. Appl., vol. 42, pp. 990-996, 2006.

[6] J. Park, B. Kim, J. Yang, K. Lee, S.B. Lee, E.J. Wiedenbrug, M. Teska, and S. Han, "Evaluation of the Detectability of Broken Rotor Bars for Double Squirrel Cage Rotor Induction Motors," In Proc. of the IEEE ECCE 2010, pp. 2493-2500, Sept. 2010.

[7] M. Riera-Guasp, J. A. Antonino-Daviu, M. Pineda-Sanchez, R. PuchePanadero, and J. Perez-Cruz, "A General Approach for the Transient Detection of Slip-Dependent Fault Components Based on the Discrete Wavelet Transform," IEEE Trans. Ind. Electron., vol. 55, pp. 41674180, 2008

[8] G. Georgoulas, M.O. Mustafa, I.P. Tsoumas, J.A. Antonino-Daviu, V. Climente-Alarcon, C.D. Stylios, and G. Nikolakopoulos, "Principal Component Analysis of the start-up transient and Hidden Markov Modeling for broken rotor bar fault diagnosis in asynchronous machines," Expert Systems with Applications, vol. 40, no. 17, pp. 7024-7033, 2013
9] P. Karvelis, G. Georgoulas, I.P. Tsoumas, J.A. Antonino-Daviu, V. Climente-Alarcon, and C.D. Stylios, "A Symbolic Representation Approach for the Diagnosis of Broken Rotor Bars in Induction Motors," IEEE Transactions on Industrial Informatics, vol. 11, no. 5, pp.1028-1037, 2015.

[10] J. Pons-Llinares, J.A. Antonino-Daviu, M. Riera-Guasp, S.B. Lee, T.J. Kang, and C. Yang, "Advanced induction motor rotor fault diagnosis via continuous and discrete time-frequency tools," IEEE Trans. Ind. Electron., vol. 62, no. 3, pp.1791-1802, 2015.

[11] G. Georgoulas, P. Karvelis, C.D. Stylios, I.P. Tsoumas, J.A. AntoninoDaviu, and V. Climente-Alarcon, "Automatizing the broken bar detection process via short time Fourier transform and twodimensional piecewise aggregate approximation representation," In Proc. IEEE ECCE 2014, pp. 3104-3110, 2014.

12] F. Briz, M.W. Degner, P. García, and D. Bragado, "Broken rotor bar detection in line-fed induction machines using complex wavelet analysis of startup transients," IEEE Trans. Ind. Appl., vol. 44, no. 3, pp.760-768, 2008

[13] V. Climente-Alarcon., J.A. Antonino-Daviu, M. Riera-Guasp, R Puche-Panadero and L. Escobar "Application of the Wigner-Ville distribution for the detection of rotor asymmetries and eccentricity through high-order harmonics," Electric Power Systems Research, vol. 91, pp.28-36, 2012.

[14] J.A. Antonino-Daviu, S. Aviyente, E.G. Strangas, and M. RieraGuasp, "Scale invariant feature extraction algorithm for the automatic diagnosis of rotor asymmetries in induction motors," IEEE Tran.s on Industrial Informatics, vol. 9, no. 1, pp.100-108, 2013.

[15] http://www.pdma.com/webinars/Rotor_Fault_Zone/Rotor.html

[16] http://www.irispower.com/Upload/Brochures/mdsp3\%20flyer\%20v1 $\% 20$ feb\%202014.pdf

[17] http://www.skf.com/binary/21-155464/PUB-CM-P2-14547-ENEXP4000-brochure.pdf

[18] A. Vellido Alcacena, J.D. Martín, F. Rossi, and P.J. Lisboa, "Seeing is believing: The importance of visualization in real-world machine .learning applications," In Proc. 19th ESANN 2011, Belgium, April 27-29, 2011, pp. 219-226.

[19] R. Burnett, J. Watson, and S. Elder, "The application of modern signal processing techniques to rotor fault detection and location within three phase induction motors", European Signal Processing Journal, vol. 49, pp. 426-431, 1996.

[20] S. Elder, J. F. Watson, and W. T. Thomson, "Fault detection in induction motors as a result of transient analysis," in Proc. IEEE 4th Int. Conf. Elect. Mach. Drives, London, U.K., pp. 182-186, 1989

[21] S. Mallat, A Wavelet Tour of Signal Processing. 2nd ed. Oxford: Academic Press, 1999

[22] A. Teolis, Computational signal processing with wavelets, Birkhauser, 1998.

[23] J.D. Ville, "Théorie et applications de la notion de signal analytique," Cables et transmission, vol. 2, no. 1, pp.61-74, 1948.

[24] E. Wigner, "On the quantum correction for thermodynamic equilibrium," Physical Review, vol. 40, no. 5, p.749, 1932.

[25] P. Flandrin, Time-frequency/time-scale analysis. Academic press, 1998.

[26] G. Georgoulas, I.P. Tsoumas, J.A. Antonino-Daviu, V. ClimenteAlarcon, C.D. Stylios, E.D. Mitronikas, and A.N. Safacas, "Automatic pattern identification based on the complex empirical mode decomposition of the startup current for the diagnosis of rotor asymmetries in asynchronous machines," IEEE Trans. Ind. Electron., vol. 61, no. 9, pp. 4937-4946, 2014.

[27] F. Auger, P. Flandrin, P. Gonçalvès, and O. Lemoine, Time Frequency Toolbox to Use with Matlab. Paris, France: Centre National de la Recherche Scientifique (CNRS), 1995/1996.

[28] V. Climente-Alarcon, J.A. Antonino-Daviu, M. Riera-Guasp, and M Vlcek, "Induction motor diagnosis by advanced notch FIR filters and the Wigner-Ville distribution," IEEE Trans. Ind. Electron., vol. 61, no. 8, pp. 4217-4227, 2014

[29] K.D. Hurst and T.G. Habetler, "Sensorless speed measurement using current harmonic spectral estimation in induction machine drives," IEEE Transactions on Power Electronics, vol. 11, no. 1, pp. 66-73, 1996 